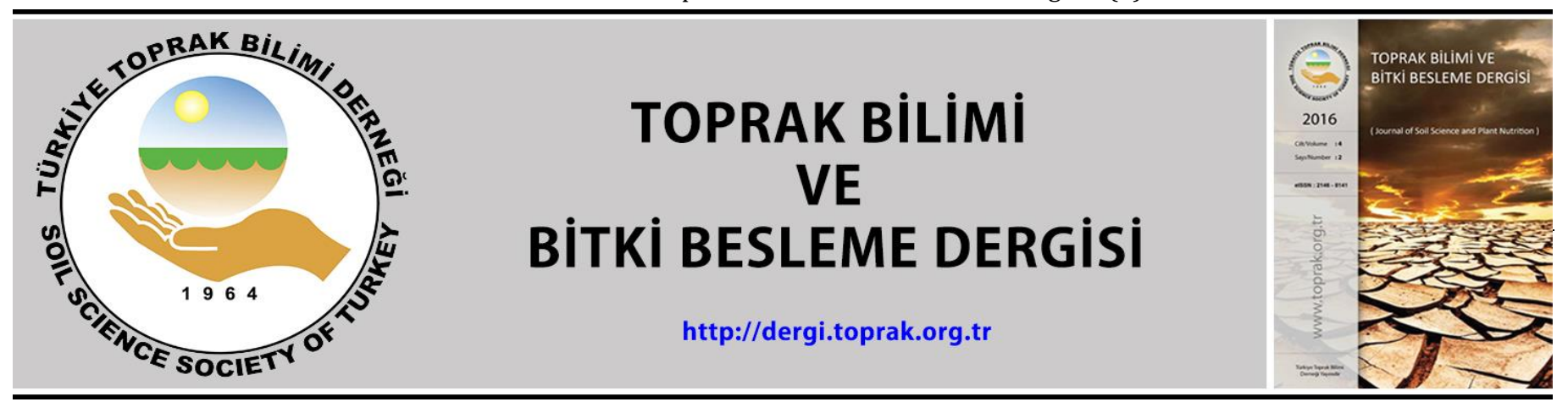

\title{
Tarla koşullarında uygulanan trifluralin herbisidinin toprakta taşınımı ve birikimi
}

\author{
Ülviye Kamburoğlu Çebi ${ }^{1, *}$, Recep Çakır ${ }^{2}$, Hasan Hayri Tok ${ }^{3}$ \\ ${ }^{1}$ Atatürk Toprak Su ve Tarımsal Meteoroloji Araştırma Enstitüsü Müdürlüğü, Kırklareli \\ ${ }^{2}$ Çanakkale Onsekiz Mart Üniversitesi, Lapseki Meslek Yüksek Okulu, Çanakkale \\ ${ }^{3}$ Namık Kemal Üniversitesi, Ziraat Fakültesi, Toprak Bilimi ve Bitki Besleme Bölümü, Tekirdağ
}

\begin{abstract}
Özet
Günümüzde tarım alanlarında en önemli amaçlardan bir tanesi, artan nüfusa ve ona paralel olarak artan gıda gereksinimi karşılamaya yönelik olarak yüksek tarımsal üretimin sağlanmasıdır. Bu bağlamda, birim alandan daha fazla verim almak amacı ile tarımda kullanılan birçok tarımsal girdi, tarımsal üretim sistemini olumsuz etkilemektedir. Herbisit girdisi bunların en önemlilerinden biri olup bașta su ve toprak gibi doğal kaynakları kirletmesi ve topraktaki kalıntıları ile bir çok makro ve mikro canlının yanı sıra, topraktan yıkanarak yer altı suyuna ve akarsu, göl ve deniz gibi su yüzeylerine ulaşarak yaşayan canlıları direkt olarak, ya da bu canlı organizmalarda birikerek besin zincirini olumsuz etkilemektedir. Araştırma, Trakya Bölgesi Turgutbey sulama sahasında üreticilerin açtıkları kuyulardan sağlanan su ile sulama uygulaması yapılan toprakları kapsamaktadır. Sahaya ait toprakların farklı katmanlarında trifluralin herbisitinin toprakta taşınımı ve kalıntı olarak birikimi irdelenmiştir. Çalışmada, farklı organik madde ve bünyeye sahip 16 farklı noktada ve 3 katmanda örnekleme yapılmıştır. Dört yıllık çalışmada, 2,4 (min.) ile 1200 (max.) ug/L düzeyinde trifluralin kalıntı miktarları belirlenmiştir. Toprak örneklerinde profillerin üst katmanlarında trifluralin miktarları daha yüksek olurken alt katlara inildiğinde konsantrasyonlarda düşme görülmektedir. Ayrıca ilkbaharda alınan topraklardaki trifluralin konsantrasyonlarının sonbaharda yaplan toprak örneklemelerindeki konsantrasyonlara oranla daha yüksek olduğu tespit edilmiştir.
\end{abstract}

Anahtar Kelimeler: Trifluralin, toprak, taşınma, birikim.

\section{Convection and accumulation of trifluralin herbicide in the soil in field conditions}

\begin{abstract}
Nowadays, one of the most important purposes in agricultural areas is to provide high agricultural production in order to supply the increasing food requirement according to the increasing population. In this context, many agricultural inputs which are used in order to get more yield from unit area effect the agricultural production system negatively. Herbicide is one the most important inputs, pollutes the natural resources such as water and soil and effects the living creatures by reaching to the rivers, lakes and seas and underground waters besides several macro and micro livings or effects the food chain by cumulating in these living organisms. This research includes the soils to which the irrigation application is done by the water in the wells in Turgutbey irrigation areas in Thrace region. Convection and accumulation of trifluralin herbicide in different layers of the soil were examined. Sampling was done in 16 different points and 3 layers which had different organic matters and structure. Trifluralin residual amounts were determined in 1200 (max.) ug/L level with 2,4 (min.). The trifluralin amounts were determined to be higher in the top layers of the profiles in the soil samples but decline in the concentrations was seen in the substratum. Besides, the trifluralin concentrations in the soils taken in spring were determined to be higher than the concentrations in the soil samples in autumn.
\end{abstract}

Keywords: Trifluralin, Soil, Convection, Accumulation.

(C) 2019 Türkiye Toprak Bilimi Derneği. Her Hakkı Saklıdır

\section{Giriş}

Hastalık ve zararlı etkisinin giderilmesinde, diğer tarımsal savaş yöntemlerine göre maliyeti düşük olan, kullanılması en kolay yol olarak görülen pestisit kullanımı, tarımsal ürünlerin verim ve kalitesini arttırmak için kaçınılmazdır. Modern tarımın vazgeçilmez bir girdisi olan pestisit kullanımı, birçok avantajının yanı sıra birçok dezavantajı da beraberinde getirmektedir. Pestisitler toprağa veya bitkiye uygulandıktan sonra

\footnotetext{
* Sorumlu yazar:

Tel. : $\quad 02882144885$

E-posta : ulviyecebi@yahoo.com
}

Geliş Tarihi : 10 Eylül 2018

Kabul Tarihi : 3 Aralık 2018

\author{
e-ISSN : 2146-8141 \\ DOI : $10.33409 /$ tbbbd.594995
}


buharlaşma, toprak profilinden yıkanma, birikme ve bulaşma gibi süreçler geçirerek çevre kirliliğine neden olmaktadırlar. Pestisitlerin ve kalıntılarının çevre üzerindeki olumsuz etkilerinin başında toksik olmaları gelir. Zararlı canlılar kadar birçok makro ve mikro düzeyde zararsız canlıyı da etkilerler. Dünya'da, Ülkemizde ve Trakya Bölgesinde kullanılan pestistler sıralamasında, etkinliği diğer pestisitlere göre daha fazla olan herbisitler birinci sırayı almaktadır. Ülkemizde kullanılan pestisit miktarı, gelişmiş ülkelerde kullanılan miktarlara göre düşük görünmesine karşın, en önemli husus pestisitlerin bölgesel açıdan farklı düzeylerde kullanılmasıdır. Polikültürel tarım yapılan bölgelerimizdeki pestisit kullanımı, ortalama değerin 2-3 mislidir (Tok, 1996). Trakya Bölgesi, ülke tarım potansiyelinde önemli bir yere sahip olup, bölgenin ekilebilir alanlarında buğday-ayçiçeği münavebesi yaygındır.

Trakya'daki buğday üretimi ülke genelinin \%13,4'nü oluştururken bu oran tarımında trifluralinin yoğun olarak kullanıldığı ayçiçeği bitkisinde \%56,3'tür. Formulasyonlarına göre yapılan pestisit sınıflamasında, trifluralin Emülsiyon Konsantre İlaçlar (EC) grubuna girmektedir. Belirtilen grup en çok kullanılan ilaç grubu olup en önemli özellikleri su ile hemen karıșmaları ve uzun süre bozunmadan kalabilmeleridir. Ayrıca trifluralin sahip olduğu fizikokimyasal özellikleri nedeniyle toprakta uzun süre kalmakta ve yeraltı su kaynaklarına ulaşabilmektedir. Yabancı otlarla mücadelede kullanılan trifluralin toprağa uygulandıktan sonra buharlaşma, toprak profilinden yıkanma, toprakta birikme, yeraltı sularına bulaşma şeklinde çevre kirliliğine neden olmaktadır. Ayrıca ayçiçeğine uygulanan trifluralin, ayçiçeği münavebesini takip eden buğday tohumlarının çimlenmesini azaltarak, tarlada anormal düşük çimlenme ve seyrek çıkışlarla karakterize edilmektedir. Belirtilen olay ise tarımda önemli bir ekonomik girdi olan tohumda ekonomik kayıplara ve verimde önemli düşüşlere neden olmaktadır.

Trifluralin EPA (Environmental Protection Agency), FAO (Food and Agriculture Organization) ve Uluslararası Kanser Araştırma Merkezi verilerine göre kanserojen bir maddedir ve suda yaşayan canlılar için düşük dozlarda yüksek derecede toksiktir. Trifluralinin ve türevlerinin bu olumsuz özelliklerinden dolayı, su ve toprak kaynaklarında hareketini ve kalıntı olarak birikmesini inceleyen bazı araştırmalar yapılmıştır (Bengtson et al., 1990; Feagley and Kim, 1995; Kim and Feagley, 2002; Kodesova et. al., 2011; Querejeta et al., 2014). Bazı araştırmacılara göre trifluralin gibi herbisitler toprağa uygulandığında onları adsorbe eden toprak yüzeyleri ile temas haline geçmektedir. Ortaya çıkan adsorbsiyon olaylarının herbisidin toprak koloidleri tarafından tutulmasını, toprak derinliğine doğru veya yüzeyden yıkanmasını, buharlașma ile uzaklaşmasını veya dayanıklılığını kontrolü altında tutmasından dolayı herbidisin topraktaki davranışlarını ve kirlilik oluşturma potansiyelini de belirlemektedir (Kim and Feagley, 1998). Yakın zamanda herbisitlerin toprak içinde değişime uğramasının ve su ile hareket etmesinin geniş ölçülerde tartışıldığı makalelere de bilimsel literatürde rastlanmaktadır (Müller et al., 2007; Arias-Esteves et. al., 2008).

Aslında tarımda uygulanan pestisitlerin toprakta kalıntı halinde birikmesi veya yıkanarak taşınmasını kontrol eden çok sayıda faktör ileri sürülmektedir. Nelson ve ark. (2000) belirtilen olaylarda sulama öncesi yapılan tarımsal uygulamaları ve pestisit uygulamalarının önemine vurgu yaparken, başkaları (Gardner ve Branham, 2001) sulama yönetimi, uygulanan herbisidin özelliklerini ve uygulama dozunu öne çıkarmaktadır. Ülkemizde trifluralin'nin 2013 yılı itibariyle kullanımı yasaklanmıştır. Fakat pestisitlerin farklı ekolojik zincirdeki biyolojik parçalanma oranları ile bitkisel ve ona bağlı olarak ta hayvansal ürünlerindeki kalıntıları ile toksik etkileri uzun yıllar sürmektedir. Yapılan araştırmada, Turgutbey sulama sahasında sulu ayçiçeği tarımı yapılan ve yetiştiriciliğinde trifluralin hebisiti kullanılan çiftçi tarlalarından toprak örneklemeleri yapılarak, trifluralinin toprak içindeki taşınımı, yıkanması ve toprakta birikmesi incelenmiștir.

\section{Materyal ve Yöntem}

\section{Materyal}

Araştırma Marmara Bölgesinin kuzey kısmında yer alan Kırklareli İlinin güneyindeki Lüleburgaz ilçesine bağlı Turgutbey yeraltı sulama projesi sahasında yürütülmüştür. İlin yüz ölçümü 655036 ha olup 41 '042' kuzey enlemi, 27014’ doğu boylamı ve 233 m yükseltide yer almaktadır. Marmara bölgesinin kuzeyinde yer alan Kırklareli ilinde iklim, topografyaya bağlı olarak değişmektedir. Kuzey-Doğuda Istranca dağları ile Karadeniz'e bakan sahil kesiminde fazla yağış alan Karadeniz iklimi, bu dağların güneye bakan iç kısımları ile Ergene platosunda yarı karasal iklim görülmektedir. Yağış güneyden kuzeye gittikçe artış göstermektedir. İlin uzun yıllar iklim verilerine göre yıllık ortalama yağışı $589.6 \mathrm{~mm}$ olarak belirlenmiştir. En çok yağış alan aylar Aralık (76,1 mm) ve Ocak (83,3 mm), en az yağıș alan aylar da Ağustos (21,7 mm) ve Eylül $(24,6 \mathrm{~mm})$ aylarıdır. Kırklareli ovasında yıllık ortalama sıcaklık 13,0 oC olup saptanan maksimum ve minimum sıcaklar $+41,6$ ile $-15,8{ }^{\circ} \mathrm{C}$ 'dir. En sicak aylar Temmuz $\left(23,3{ }^{\circ} \mathrm{C}\right)$ ve Ağustos $\left(22,6{ }^{\circ} \mathrm{C}\right)$, en soğuk aylar da Ocak $\left(2,6^{\circ} \mathrm{C}\right)$ 
ve Şubat $\left(3,9^{\circ} \mathrm{C}\right)$ aylarıdır. Ortalama nisbi nem \% 70, buharlaşma 1099,2 $\mathrm{mm}$ ve rüzgar hızı da 2,3 $\mathrm{m} / \mathrm{s}$ olarak tespit edilmiștir. Kırklareli ilinde xeric-ustic nem rejimi, mesic sıcaklık rejimi ve Marmara (AkdenizKaradeniz) geçiş tipi yağış rejimi hakimdir (Dinç ve ark., 1995).

Turgutbey yeraltı sulama sahasının hakim toprak grubu alüviyal'dir. Bu topraklar, akarsular tarafından taşınıp depolanan materyaller üzerinde oluşan AC profilli genç topraklardır. Mineral bileşikleri akarsu havzasının litolojik bileșimi ile jeolojik periyotlarda yer alan toprak gelişimi sırasındaki erozyon ve birikme devirlerine bağlı olup heterojendir. Profillerinde horizonlaşma ya hiç yok ya da çok az belirgindir. Buna karşılık değişik özellikte katlar görülür, çoğu yukarı arazilerden yıkanan kireççe zengindir. Alüviyal topraklar, bünyelerine veya bulundukları bölgelere yahut evrim devrelerine göre sinıflandırılırlar. Bunlarda üst toprak alt toprağa belirsiz olarak geçiş yapar. İnce bünyeli ve taban suyu yüksek olanlarda düşey geçirgenlik azdır. Yüzey nemli ve organik maddece zengindir. Alt toprakta hafif seyreden bir indirgenme olayı hüküm sürer. Kaba bünyeliler iyi drene olduğundan yüzey katlar çabuk kurur. Bulundukları iklime uyabilen her türlü kültür bitkisinin yetiștirilmesine elverișli ve üretken topraklardır. Çalıșma alanına topraklarına ait bazı fiziksel ve kimyasal özellikleri Çizelge 1'de verilmiștir.

\section{Trifluralinin fizikokimyasal özellikleri}

Trifluralin'in kapalı kimyasal formülü: $\mathrm{C}_{13} \mathrm{H}_{16} \mathrm{~F}_{3} \mathrm{~N}_{3} \mathrm{O}_{4}$. Trifluralin'in açık kimyasal formülü Şekil 1'de verilmiștir. Pestisitlerin kirlilik potansiyelleri toprak ve iklim gibi faktörlerin yanı sıra, pestisitin dayanıklılığına, buharlaşma özelliğine ve topraktaki hareketliliğine bağlıdır. Bir pestisitin topraktaki dayanıklılığı ise persistans süresine göre değisşir ve araştırma konusu olan herbisit, Türkiye'de yaygın olarak kullanılan pestisitlerin sinıflamasında, dayanıklılığı en fazla olan pestisitler grubunda yer aldığı bilinmektedir. Bir diğer özellik olan buharlaşma sabitesine (Henry sabiti-KH) göre, buharlaşmanın yüksek olduğu sınıflama grubunda yer alan trifluralin $\left(\mathrm{KH}=2,5^{*} 10^{-5}\right)$, topraktaki hareketliliği açısından hareketliliğin en düşük olduğu tarım ilaçları arasında bulunmaktadır. Araştırma konusu edilen trifluralinin başlıca özellikleri Çizelge 2'de özetlenmiştir.

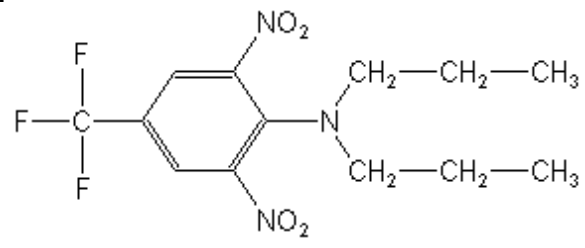

Şekil 1. Trifluralin'in açık kimyasal formülü

Çizelge 2. Trifluralinin bazı fiziksel, kimyasal ve toksikolojik özellikleri

\begin{tabular}{ll}
\hline CAS Registry Number & $1582-09-8$ \\
Chemical formula & $\mathrm{C}_{13} \mathrm{H}_{16} \mathrm{~F}_{3} \mathrm{~N}_{3} \mathrm{O}_{4}$ \\
Molar mass & $335.28 \mathrm{~g} / \mathrm{mol}$ \\
Appearance & Yellow crystals \\
Melting point & 46 to $47^{\circ} \mathrm{C}\left(115\right.$ to $117^{\circ} \mathrm{F} ; 319$ to $\left.320 \mathrm{~K}\right)$ \\
Boiling point & 139 to $140^{\circ} \mathrm{C}\left(282\right.$ to $284^{\circ} \mathrm{F} ; 412$ to $\left.413 \mathrm{~K}\right)$ (at $\left.4.2 \mathrm{mmHg}\right)$ \\
Solubility in water & $0.0024 \mathrm{~g} / 100 \mathrm{~mL}$
\end{tabular}

Lethal dose or concentration $(L D, L C)$ :

$L D_{50}$ (Median dose) $500 \mathrm{mg} / \mathrm{kg}$ (rat, oral)

\section{Yöntem}

Turgutbey sulama sahasında sulu ayçiçeği tarımı yapan çiftçi tarlalarında bulunan sulama kuyularını çevreleyen arazilerden 16 örnekleme noktası belirlenmiștir. Trifluralinin topraktaki durumu ve yeraltı suyuna doğru hareketini tahmin etmek amacıyla, herbisit uygulamasından yaklaşık 10 gün sonra ve sonbaharda olmak üzere toprağın 0-30 cm, 30-60 cm, 60-100 cm derinliklerinden bozulmuş toprak örnekleri alınarak trifluralin kalıntı belirleme çalışmaları yapılmıştır. Örnekleme noktaları Şekil 2'de verilmiştir. 


\begin{tabular}{|c|c|c|c|c|c|c|c|c|c|c|}
\hline $\begin{array}{l}\text { Profil } \\
\text { No }\end{array}$ & $\begin{array}{l}\text { Derinlik, } \\
\mathrm{Cm}\end{array}$ & $\begin{array}{c}\text { İşba, } \\
\%\end{array}$ & $\mathrm{pH}$ & $\begin{array}{c}\mathrm{OM}^{1}, \\
\%\end{array}$ & $\begin{array}{c}\mathrm{TK}^{2}, \\
\%\end{array}$ & $\begin{array}{c}\mathrm{SN}^{3}, \\
\%\end{array}$ & $\begin{array}{l}\text { Kil, } \\
\%\end{array}$ & $\begin{array}{c}\text { Silt, } \\
\%\end{array}$ & $\begin{array}{c}\text { Kum, } \\
\%\end{array}$ & $\begin{array}{c}\mathrm{KDK}^{4} \\
\mathrm{me} / 100 \mathrm{~g}\end{array}$ \\
\hline \multirow[t]{3}{*}{1} & $0-30$ & 66 & 7.70 & 1.98 & 36.64 & 20.30 & 35.57 & 25.84 & 38.59 & 30.50 \\
\hline & $30-60$ & 66 & 7.94 & 1.00 & 38.66 & 22.44 & 40.35 & 21.89 & 37.76 & 37.63 \\
\hline & $60-100$ & 70 & 7.82 & 0.73 & 31.88 & 16.61 & 34.99 & 25.41 & 39.60 & 20.00 \\
\hline \multirow[t]{3}{*}{2} & $0-30$ & 64 & 7.71 & 1.27 & 31.49 & 16.68 & 35.26 & 21.41 & 43.33 & 25.78 \\
\hline & $30-60$ & 66 & 7.70 & 0.79 & 44.74 & 35.54 & 35.70 & 35.70 & 19.56 & 28.22 \\
\hline & $60-100$ & 63 & 7.88 & 0.62 & 46.90 & 34.44 & 29.31 & 29.31 & 23.79 & 25.39 \\
\hline \multirow[t]{3}{*}{3} & $0-30$ & 62 & 7.34 & 1.71 & 30.88 & 15.30 & 26.73 & 25.49 & 47.78 & 22.30 \\
\hline & $30-60$ & 66 & 7.78 & 0.89 & 37.82 & 20.59 & 35.75 & 19.59 & 44.66 & 32.40 \\
\hline & $60-100$ & 63 & 8.12 & 0.62 & 39.72 & 22.51 & 40.33 & 19.74 & 39.93 & 29.10 \\
\hline \multirow[t]{3}{*}{4} & $0-30$ & 53 & 6.65 & 1.60 & 31.09 & 21.89 & 28.86 & 25.72 & 45.62 & 31.48 \\
\hline & $30-60$ & 58 & 7.18 & 0.89 & 34.84 & 25.14 & 35.34 & 23.84 & 40.82 & 29.76 \\
\hline & $60-100$ & 62 & 8.06 & 0.62 & 30.42 & 21.63 & 30.67 & 31.54 & 37.39 & 36.58 \\
\hline \multirow[t]{3}{*}{5} & $0-30$ & 68 & 7.58 & 2.80 & 35.86 & 25.64 & 48.00 & 23.15 & 28.85 & 36.89 \\
\hline & $30-60$ & 63 & 8.89 & 1.16 & 36.11 & 29.31 & 52.81 & 21.25 & 25.94 & 30.24 \\
\hline & $60-100$ & 58 & 8.00 & 0.89 & 37.18 & 28.48 & 55.05 & 21.29 & 23.66 & 33.19 \\
\hline \multirow[t]{3}{*}{6} & $0-30$ & 63 & 7.56 & 1.44 & 35.20 & 25.98 & 39.73 & 26.06 & 34.21 & 32.31 \\
\hline & $30-60$ & 70 & 7.66 & 1.00 & 36.17 & 26.01 & 39.99 & 26.23 & 33.78 & 34.45 \\
\hline & $60-100$ & 72 & 7.94 & 0.79 & 35.09 & 24.02 & 42.12 & 26.22 & 31.66 & 33.51 \\
\hline \multirow[t]{3}{*}{7} & $0-30$ & 48 & 6,83 & 1,55 & 13.26 & 5.37 & 5.48 & 26.39 & 68.13 & 10.45 \\
\hline & $30-60$ & 44 & 7.56 & 0,89 & 18.08 & 7.76 & 11.65 & 22.49 & 65.86 & 10.86 \\
\hline & $60-100$ & 50 & 7,99 & 0,62 & 27.46 & 13.46 & 22.24 & 29.11 & 48.65 & 15.88 \\
\hline \multirow[t]{3}{*}{8} & $0-30$ & 50 & 8.04 & 0.89 & 16.46 & 6.17 & 9.56 & 34.61 & 55.83 & 10.45 \\
\hline & $30-60$ & 48 & 7.80 & 0.45 & 17.22 & 6.30 & 9.57 & 36.67 & 53.76 & 9.43 \\
\hline & $60-100$ & 48 & 8.00 & 0.84 & 19.80 & 7.73 & 13.71 & 38.91 & 47.38 & 13.07 \\
\hline \multirow[t]{3}{*}{9} & $0-30$ & 63 & 7.56 & 1.44 & 35.20 & 25.98 & 39.73 & 26.06 & 34.21 & 32.31 \\
\hline & $30-60$ & 70 & 7.66 & 1.00 & 36.17 & 26.01 & 39.99 & 26.23 & 33.78 & 31.81 \\
\hline & $60-100$ & 72 & 7.94 & 0.79 & 35.09 & 24.02 & 42.12 & 26.22 & 31.66 & 33.24 \\
\hline \multirow[t]{3}{*}{10} & $0-30$ & 64 & 7.54 & 1.44 & 20.28 & 9.28 & 37.61 & 21.26 & 41.13 & 40.32 \\
\hline & $30-60$ & 68 & 7.78 & 0.79 & 22.09 & 10.57 & 35.85 & 23.48 & 40.67 & 37.19 \\
\hline & $60-100$ & 63 & 8.02 & 0.45 & 26.10 & 15.99 & 33.81 & 25.68 & 40.51 & 40.54 \\
\hline \multirow[t]{3}{*}{11} & $0-30$ & 57 & 6.98 & 1.16 & 36.10 & 21.17 & 45.58 & 23.01 & 31.41 & 32.31 \\
\hline & $30-60$ & 59 & 6.99 & 0.62 & 37.41 & 21.59 & 50.20 & 23.18 & 26.62 & 35.21 \\
\hline & $60-100$ & 66 & 7.47 & 0.62 & 33.84 & 18.64 & 51.62 & 23.17 & 25.21 & 33.98 \\
\hline \multirow[t]{2}{*}{12} & $0-30$ & 46 & 6.95 & 0.89 & 27.52 & 17.05 & 22.21 & 18.52 & 59.27 & 13.84 \\
\hline & $30-60$ & 50 & 7.73 & 0.51 & 31.45 & 17.68 & 24.41 & 16.55 & 59.04 & 16.32 \\
\hline \multirow[t]{3}{*}{13} & $0-30$ & 50 & 6.28 & 1.44 & 22.96 & 14.10 & 35.52 & 21.15 & 43.33 & 28.57 \\
\hline & $30-60$ & 55 & 7.11 & 0.73 & 24.82 & 15.66 & 37.88 & 19.15 & 42.97 & 29.33 \\
\hline & $60-100$ & 55 & 7.83 & 0.34 & 30.87 & 21.08 & 30.45 & 18.97 & 50.69 & 22.42 \\
\hline \multirow[t]{3}{*}{14} & $0-30$ & 48 & 6.55 & 1.55 & 29.00 & 19.77 & 28.12 & 14.69 & 57.19 & 20.34 \\
\hline & $30-60$ & 48 & 7.30 & 0.45 & 35.20 & 24.61 & 30.37 & 12.66 & 56.97 & 22.86 \\
\hline & $60-100$ & 46 & 7.49 & 0.34 & 34.01 & 22.94 & 35.73 & 16.79 & 47.48 & 29.11 \\
\hline \multirow[t]{3}{*}{15} & $0-30$ & 57 & 6.99 & 0.89 & 33.03 & 21.41 & 48.19 & 18.98 & 32.83 & 27.70 \\
\hline & $30-60$ & 50 & 7.29 & 0.84 & 34.39 & 20.82 & 48.08 & 16.81 & 35.11 & 35.21 \\
\hline & $60-100$ & 59 & 7.32 & 0.51 & 29.88 & 17.09 & 43.33 & 18.72 & 37.95 & 33.33 \\
\hline \multirow[t]{3}{*}{16} & $0-30$ & 48 & 5.52 & 1.33 & 26.06 & 16.40 & 34.67 & 22.76 & 42.57 & 30.58 \\
\hline & $30-60$ & 50 & 6.10 & 0.89 & 34.63 & 22.76 & 46.27 & 16.92 & 36.81 & 39.29 \\
\hline & $60-100$ & 66 & 7.05 & 0.34 & 34.51 & 21.03 & 48.12 & 18.95 & 32.93 & 38.54 \\
\hline
\end{tabular}

$\begin{array}{lll}1 & & \end{array}$ (organik madde) $\quad{ }^{2}$ TK (Tarla kapasitesi) ${ }^{3} \mathrm{SN}$ (Solma noktası) $\quad{ }^{4}$ KDK (Katyon değişim kapasitesi)

\section{Analiz Yöntemleri}

Trifluralin Kalıntı Analizi- Trifluralin analizleri PERICHROM PR 2100 marka gaz kromotografi cihazı ile yapılmıştır. Kullanılan dedektör ECD (Elektron Yakalama Dedektörü), kolon kapilar olup 0,32 mm iç çapında ve 25 m uzunluğundadır. Toprak analizlerinde EPA 3541 nolu soxhlet ekstraksiyon yöntemi kullanılmıștır. Yöntemde 5 g toprak örneği ve 1:1 aseton-hexan ekstraksiyon karışımı kullanılmıştır. Toprak örneği tipik kromotogramı Şekil 3'te verilmiştir. 


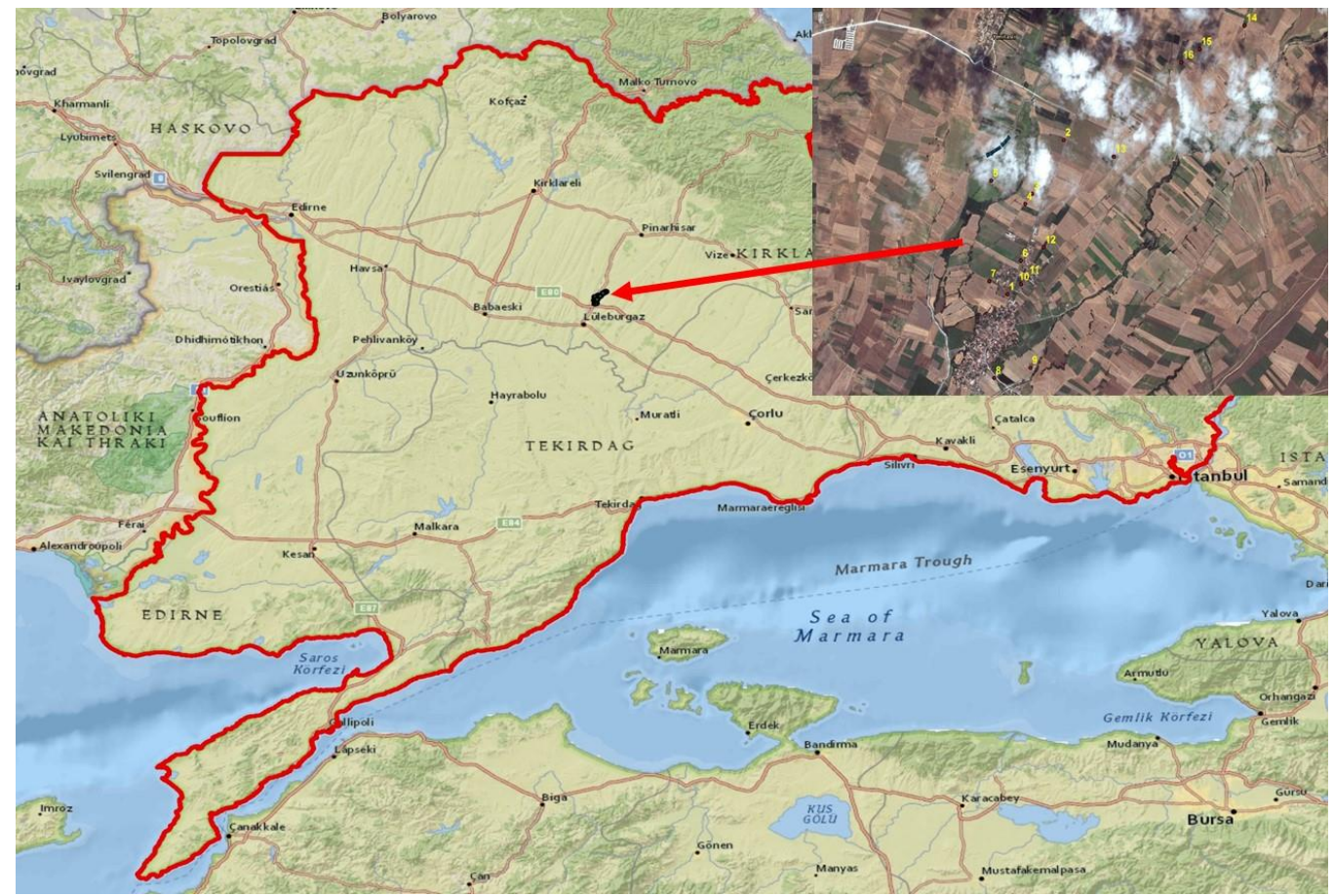

Şekil 2. Turgutbey sulama sahası alanı haritası (K-sulama kuyuları)

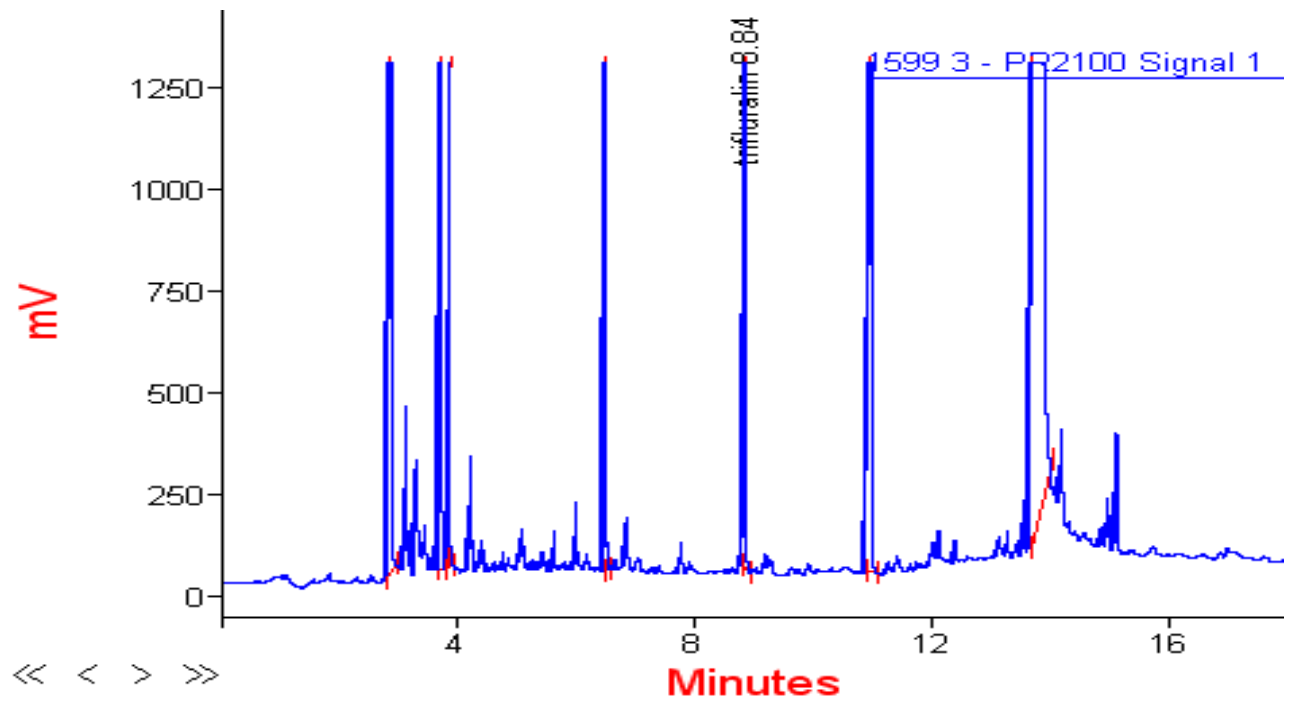

Şekil 3. Toprak örneği tipik bir kromotogram

2-Ethyl-4-nitro-6-(trifluromethyl)-1H-benzimidazole türevi Yunanistan Ioannina Üniversitesi Kimya Bölümü'de Prof Dr. A. Albanis tarafından CG-MS ortamında kimliği tanımlanmıştır. Tarla kapasitesi $1 / 3$ atmosfer basınç altında, poroz levhalı basınç aleti ile Richards (1954) yöntemine göre yapılmıştır. Solma noktası 15 atmosfer basınç altında, poroz levhalı basınç aleti ile Richards (1954) yöntemine göre yapılmıștır. Bünye analizi Bouyoucus hidrometre yöntemiyle yapılmıştır (Richards, 1954). Saturasyon yüzdesi toprak sature oluncaya kadar saf su ilavesi ile belirlenmiştir (Tüzüner, 1990). Organik madde modifiye edilmiş Walkley Black yöntemi ile yapılmıştır (Richards, 1954). Toprak reaksiyonu saturasyon ekstraktında cam elektrotlu pH metre ile yapılmıştır (Sağlam, 1994). Katyon değişim kapasitesi (KDK) belli bir miktar toprak pH'sı 8,2'ye ayarlı 1,0 N sodyum asetat ile doyurulup, etil alkol ile yıkandıktan sonra 1,0 N amonyum asetat ile ekstrakte edilerek flame fotometresi ile $\mathrm{Na}^{+}$miktarı saptanıp, buna göre KDK me/100g toprak cinsinden belirlenmiştir (Sağlam, 1994).

\section{Bulgular ve Tartışma}

Sulu ayçiçeği tarımı yapılan Turgutbey sulama sahasında dört yıl boyunca 16 noktadan ve farklı katmandan alınan toprak örneklerinde yapılan trifluralin kalıntı analizi sonuçları Çizelge 3’te verilmiştir. 
Çizelge 3. Topraklarında belirlenen trifluralin kalıntı miktarları

\begin{tabular}{|c|c|c|c|c|c|c|c|c|c|}
\hline \multirow[t]{2}{*}{$\begin{array}{l}\text { Profil } \\
\text { No }\end{array}$} & \multirow[t]{2}{*}{$\begin{array}{l}\text { Derinlik } \\
\text { (cm) }\end{array}$} & \multicolumn{2}{|c|}{$\begin{array}{c}2007 \text { Yılı } \\
\text { Trifluralin (ug/L) }\end{array}$} & \multicolumn{2}{|c|}{$\begin{array}{c}2006 \text { Yllı } \\
\text { Trifluralin (ug/L) }\end{array}$} & \multicolumn{2}{|c|}{$\begin{array}{c}2005 \text { Yılı } \\
\text { Trifluralin (ug/L) }\end{array}$} & \multicolumn{2}{|c|}{$\begin{array}{c}2004 \text { Yılı } \\
\text { Trifluralin (ug/L) }\end{array}$} \\
\hline & & İlkbahar & Sonbahar & İlkbahar & Sonbahar & İlkbahar & Sonbahar & İlkbahar & Sonbahar \\
\hline \multirow{3}{*}{1} & $0-30$ & 15.8 & 10.5 & 1200.0 & 34.4 & 39.0 & 20.1 & 54.9 & 57.7 \\
\hline & $30-60$ & 13.2 & 5.7 & 1039.8 & 28.4 & 12.5 & 15.1 & 44.1 & 23.5 \\
\hline & $60-100$ & 0 & 0 & 706.0 & 25.8 & 13.9 & 14.2 & 56.2 & 39.7 \\
\hline \multirow{3}{*}{2} & $0-30$ & 117.4 & 80.3 & 962.7 & 75.8 & 17.4 & 10.5 & 56.2 & 43.0 \\
\hline & $30-60$ & 32.2 & 54.9 & 676.6 & 27.9 & 12.3 & 15.2 & 59.1 & 37.3 \\
\hline & $60-100$ & 21.4 & 5.6 & 77.8 & 98.4 & 29.0 & 12.4 & 23.6 & 28.8 \\
\hline \multirow{3}{*}{3} & $0-30$ & 25.7 & 22.4 & 59.4 & 32.2 & 50.0 & 30.1 & 110.0 & 121.6 \\
\hline & $30-60$ & 0 & 5.8 & 38.4 & 50.6 & 42.5 & 40.2 & 49.4 & 37.5 \\
\hline & $60-100$ & 14.4 & 0 & 30.1 & 125.8 & 27.9 & 20.6 & 40.4 & 33.3 \\
\hline \multirow{3}{*}{4} & $0-30$ & 0 & 0 & 202.3 & 41.8 & 22.7 & 20.7 & 79.4 & 34.0 \\
\hline & $30-60$ & 0 & 5.2 & 83.1 & 46.3 & 30.0 & 25.0 & 154.2 & 20.1 \\
\hline & $60-100$ & 0 & 0 & 31.6 & 20.2 & 35.7 & 15.0 & 205.2 & 40.7 \\
\hline \multirow{3}{*}{5} & $0-30$ & 17.0 & 6.0 & 0 & 26.9 & 56.2 & 35.2 & 89.4 & 48.8 \\
\hline & $30-60$ & 0 & 0 & 30.5 & 46.8 & 53.2 & 40.3 & 56.0 & 130.8 \\
\hline & $60-100$ & 38.4 & 6.3 & 45.9 & 22.3 & 53.8 & 20.0 & 53.2 & 27.5 \\
\hline \multirow{3}{*}{6} & $0-30$ & 49.6 & 52.9 & 33.5 & 94.1 & 54.0 & 40.3 & 231.1 & 106.3 \\
\hline & $30-60$ & 15.0 & 5.7 & 0 & 46.8 & 44.2 & 45.2 & 80.5 & 61.1 \\
\hline & $60-100$ & 38.4 & 53.5 & 0 & 22.3 & 43.0 & 25.0 & 90.1 & 40.8 \\
\hline \multirow{3}{*}{7} & $0-30$ & 17.9 & 5.5 & 0 & 0 & 584.0 & 120.4 & 54.3 & 47.0 \\
\hline & $30-60$ & 16.0 & 6.3 & 0 & 0 & 64.8 & 100.2 & 185.2 & 43.9 \\
\hline & $60-100$ & 0 & 2.4 & 24.8 & 45.3 & 45.4 & 40.3 & 172.5 & 46.1 \\
\hline \multirow{3}{*}{8} & $0-30$ & 17.4 & 8.9 & 22.6 & 38.2 & 379.7 & 150.7 & 50.8 & 0 \\
\hline & $30-60$ & 0 & 5.5 & 21.9 & 31.3 & 72.2 & 55.0 & 38.5 & 46.4 \\
\hline & $60-100$ & 38.4 & 25.6 & 22.1 & 72.2 & 183.5 & 100.1 & 61.7 & 44.5 \\
\hline \multirow{3}{*}{9} & $0-30$ & 21.3 & 6.0 & 45.4 & 49.0 & 100,6 & 90.6 & 41.8 & 45.1 \\
\hline & $30-60$ & 27.3 & 6.5 & 101.6 & 29.4 & 23.2 & 40.3 & 61.1 & 24.2 \\
\hline & $60-100$ & 23.2 & 10.2 & 153.7 & 31.6 & 47.0 & 30.1 & 1328.3 & 53.8 \\
\hline \multirow{3}{*}{10} & $0-30$ & 26.4 & 15.6 & 15.2 & 34.0 & 127.1 & 80.6 & 619.8 & 924.6 \\
\hline & $30-60$ & 0 & 4.8 & 29.2 & 29.6 & 52.8 & 40.1 & 99.4 & 45.5 \\
\hline & $60-100$ & 26.1 & 0 & 78.0 & 23.5 & 37.0 & 20.2 & 173.9 & 39.7 \\
\hline \multirow{3}{*}{11} & $0-30$ & 41.2 & 18.4 & 41.6 & 33.1 & 37.4 & 35.1 & * & * \\
\hline & $30-60$ & 31.7 & 5.5 & 0 & 33.8 & 54.3 & 20.2 & $*$ & * \\
\hline & $60-100$ & 51.4 & 3.4 & 23.4 & 34.9 & 81.8 & 40.8 & $*$ & $*$ \\
\hline \multirow[t]{2}{*}{$12^{* *}$} & $0-30$ & 839.0 & 539.1 & 137.2 & 67.3 & 496.0 & 90.7 & 351.0 & 119.2 \\
\hline & $30-60$ & 51.2 & 120.1 & 46.0 & 33.0 & 65.7 & 120.7 & 81.6 & 42.8 \\
\hline \multirow[t]{3}{*}{13} & $0-30$ & 646.0 & 332.7 & 1225.8 & 41.6 & 482.4 & 120.1 & 1344.4 & 74.8 \\
\hline & $30-60$ & 62.87 & 54.0 & 51.3 & 35.2 & 37.1 & 95.2 & 175.2 & 210.0 \\
\hline & $60-100$ & 26.5 & 45.9 & 18.3 & 30.0 & 24.1 & 50.6 & 41.3 & 29.7 \\
\hline \multirow[t]{3}{*}{14} & $0-30$ & 79.9 & 35.8 & 1254.0 & 38.2 & 578.2 & 100.2 & 100.1 & 25.2 \\
\hline & $30-60$ & 65.0 & 29.4 & 92.6 & 24.8 & 55.3 & 120.7 & 75.8 & 24.4 \\
\hline & $60-100$ & 0 & 5.2 & 21.8 & 124.0 & 38.9 & 85.0 & 110.8 & 25.3 \\
\hline 15 & $0-30$ & 531.0 & 366.4 & 70.9 & 18.3 & 31.1 & 20.1 & $*$ & * \\
\hline & $30-60$ & 22.8 & 36.1 & 19.4 & 33.2 & 53.4 & 40.2 & $*$ & $*$ \\
\hline & $60-100$ & 0 & 8.2 & 25.6 & 26.7 & 78.2 & 35.4 & $*$ & * \\
\hline 16 & $0-30$ & 472.3 & 232.9 & 105.6 & 23.5 & 45.6 & 27.7 & $*$ & $*$ \\
\hline & $30-60$ & 560.4 & 235.9 & 40.2 & 44.4 & 30.5 & 16.2 & $*$ & $*$ \\
\hline & $60-100$ & 22.5 & 26.2 & 21.9 & 29.5 & 37.9 & 30.2 & $*$ & $*$ \\
\hline
\end{tabular}

* 11, 15 ve 16 nolu noktalardan 2005 yllından örnek alınmaya başlanmıştır.

** 12 nolu profilin sığ olması nedeniyle iki katmandan örnekleme yapılmıştır.

Tabloda yer alan verilere göre; 2004 yılında belirlenen en yüksek kalıntı miktarları ilkbaharda 1344,4 ug/L, sonbaharda 924,6 ug/L iken belirlenen en düşük kalıntı miktarları ise ilkbaharda 23,6 ug/L, sonbaharda 20,1 ug/L'dir. 2005 yllında ilkbahar ve sonbaharda alınan toprak örneklerinde belirlenen en yüksek trifluralin miktarları sırasıyla 584,0 ile 150,7 ug/L iken, en düşük konsantrasyonlar 12,5 ile 12,4 olmuştur. 2006 yılında trifluralin uygulamasından yaklaşık on gün sonra alınan ilkbahar örneklemelerinde belirlenen 
en yüksek ve en düşük trifluralin miktarları 1254,0 ile 15,2 ug/L iken söz konusu değerler sonbaharda 125,8 ile 20,2 ug/L olarak tespit edilmiştir. 2007 yll ilkbahar döneminin topraklarında belirlene max. ve min. değerler 839,0 ile 13,2 ug/L, sonbaharda belirlenen değerler de sirasiyla 539,1 ile 2,4 ug/L olduğu belirlenmiştir. Dört yılda ilkbahar döneminde alınan toprak örneklerinde en yüksek trifluralin miktarları 0$30 \mathrm{~cm}$ 'lik derinlikte belirlenmiştir. En düşük trifluralin kalıntı miktarları da genelde $60-100 \mathrm{~cm}$ 'lik toprak katmanında belirlenmiştir. 2004 yılında Turgutbey sulama sahasından alınan topraklarda belirlenen trifluralin kalıntı miktarları 9, 10, 12 ve 13 nolu profillerde, 2005 yılında 7, 8, 12, 13 ve 14 nolu profillerde yüksek oranlarda belirlenmiștir. 2006 yılında ise en yüksek kalıtı miktarları 1, 2, 13 ve 14 nolu profillere ait topraklarda belirlenmiştir. 2007 yılında sulama kuyularının yakınındaki arazilerden, mevsim başında ve mevsim sonunda alınan toprak örneklerine ait analiz sonuçlarına göre en yüksen trifluralin kalıntıları 2, 12, 13, 15 ve 16 profillere ait topraklarda belirlenmiştir. Sonuçlardan yola çlkarak üreticilerle görüşmeler yapılmış ve elde edilen bilgilere göre, trifluralin kalıntılarının düşük çıktığı noktalarda ve söz konusu yılda üreticilerin trifluralin kullanmadığı ortaya çıkmıştır.

Elde edilen sonuçlara göre; Turgutbey sulama sahasında 2004, 2005, 2006 ve 2007 yıllarına ait toprak analiz sonuçları irdelendiğinde genel olarak profillerin üst katmanlarında trifluralin miktarları daha yüksek olurken alt katlara inildiğinde konsantrasyonlarda düşme görülmüştür. Turgutbey sulama sahasındaki toprakların üst katmanlarındaki (0-30) organik madde oranları 2,80 ile 0,89 iken bu oran 60-100 cm'lik derinlikte 0,89 ile 0,34 arasındadır. Trifluralin topraktaki hareketliliği bir yönü ile çözünürlüğünün çok düşük oluşu, diğer taraftan kolay bir şekilde adsorbe olmasından dolayı zayıftır. Trifluralinin topraktaki kalıcılığı topraktaki kil ve organik madde miktarı ile doğru orantılı, nem miktarı ile de ters orantılıdır. Organik madde ile trifluralinin toprak tarafından adsorbsiyonunu irdeleyen birçok çalışma yapılmıştır. Moyer (1979)'a göre trifluralin adsorbsiyonunu topraktaki organik madde miktarı ve mevcut nem belirlemektedir. Francioso ve ark. (1992)'na göre de trifluralin adsorbsiyonu organik maddenin yüksek olduğu topraklarda daha fazladır. Tok (1996) birçok pestisidin toprakta bıraktığı kalıntı miktarının toprak organik maddesi ile önemli ve pozitif bir ilişki oluşturduğunu belirtmektedir. Organik madde varlığının toprakta trifluralin adsorbsiyonu artırdığını belirleyen bir diğer çalışma da Tavares ve Rezende (1998) tarafından yürütülmüştür. Boivin ve ark. (2005) trifluralinin toprağa kuvvetli bir şekilde bağlandığını ve organik madde ile bağlanma arasında pozitif bir ilişki olduğunu $\left(\mathrm{R}=0,82^{*}\right)$ vurgulamışlardır. Aynı kaynakta trifluralin'in artazine oranla toprak tarafından daha kuvvetli bir şekilde tutulduğu belirtilmektedir. Slovenya'da Pintar ve ark. (1996) tarafından atrazin ile yürütülen çalıșmada da herbisitin çok büyük bir kısmının toprağın sürüm katında kaldığı ve toprakta biriken atrazin'in taban suyuna doğru hareketinin çok yavaş olduğu belirtilmiş ve herbisit yıkanmasının yağış koşulları ile çok yakından ilgisi olduğu tespit edilmiştir.

Trifluralinin topraklardaki limit değerleri üzerine geliştirilmiş herhangi bir standart bulunmadığından Turgutbey sulama sahasındaki topraklarda bulunan değerlerin toksisite seviyesi konusunda bir yorum yapmak mümkün değildir. Esasen toprakta çok fazla miktardaki etmen (tekstür, organik madde, nem, toprak sıcaklığı gibi) bu tip bir standart değerlendirmesini zorlaştırmaktadır. Turgutbey sulama sahasından ilkbaharda alınan topraklardaki trifluralin konsantrasyonları sonbaharda alınan topraklardaki konsantrasyonlara oranla daha yüksek olarak belirlenmiştir. Sulama sahasından ilkbaharda toprak örnekleri trifluralin uygulamasının takip eden yaklaşık 10 günlük süreç içerisinde alındığından dolayı sonbaharda alınan örneklerdeki trifluralin miktarlarından daha yüksek olarak belirlenmiştir. Trifluralin toprağa uygulandıktan sonra sıcaklık, nem, sşık ve rüzgâr faktörlerin etkisiyle buharlaşmakta, parçalanmakta ve yıkanmaktadır. Kaynakların da doğruladığı gibi; Johnstone ve ark. (1998) göre trifluralinin topraktaki mevcudiyeti aynı zamanda iklim faktörleri ile ilişkili olup, iklim faktörlerinden yağış ve maksimum sıcaklık degradasyon açısından en etkili faktörlerdir. Tok (1997) trifluralin'in topraktaki kalıcılık süresinin uygulama dozu, yüzeydeki toprak sıcaklığı ve topraktaki nem oranı gibi birçok faktöre bağlı olmakla birlikte, topraktaki dayanıklılığı yüksek, hareketliliği çok düşük olan bir madde olduğunu ve yapılan araştırmalara göre trifluralin beş ile altı ay sonra bile toprakta belirlenebildiğini ifade etmiştir. Moore ve ark. (2007) Missisippi Deltasındaki Beasley Göl'ünde yaptıkları çalışmada organik karbonun ve kil miktarının artması ile triflularinin de tutunma oranının artığını belirtmektedirler.

Toprağa uygulanan trifluralin miktarının çok düşük bir kısmı toprakta kalıntı olarak belirlenmiştir. Trifluralin toprağa uygulandıktan sonra bir kısmı kimyasal ve mikrobiyal bozunma süreçleri geçirerek ana maddenin türevlerini oluşturmaktadır ve önemli bir kısmı da buharlaşarak kaybolmaktadır. Trifluralinin topraktan buharlaşması ile ilgili yapılan çalışmalarda yer alan bilgilere göre; trifluralin'nin fazla uçuculuk özelliği nedeniyle, toprağa direkt olarak uygulanan formülasyonlar şeklinde kullanılmaktadır ve uygulanan 
alanların nemli ve sıcak olması durumunda, topraktan buharlaşan herbisit kalıntı miktarı, toplam uygulanan miktarın \%40'ına ulaşmaktadır (Tok, 1997). Bedos ve ark. (2002)'ı da trifluralin uygulamasını takip eden 8 günlük kümülatif buharlaşma oranını toplam ilave maddenin $\% 30 \mathrm{u}$ olarak belirlemişlerdir. Aynı araştırmacıların (2006) yaptıkları bir diğer çalışmada trifluralinin buharlaşma kayıplarının \%99'unun, trifluralinin toprakla mikrobiyal ya da kimyasal olarak etkinleşmeden önceki zamanda, uygulamayı takip eden 6 gün içerisinde olduğunu belirtmişlerdir. Hollingsworth (1980)'a göre de nemli topraktaki trifluralin buharlaşması kuru topraktaki buharlaşmadan daha fazla olmuştur. Trifluralin buharlaşmasının nemli topraklarda daha yüksek düzeyde olduğu vurgulayan bir diğer çalışma da Harper ve ark. (2000) tarafından yürütülmüştür. Harper gece saatlerinde topraktaki nem oranın artmasıyla buharlaşmanın gündüz saatlerine oranla daha fazla olduğunu tespit etmiştir. Spencer ve Cliath (1974) trifluralin buharlaşmasının her $10^{\circ} C^{\prime} l i k$ sıcaklık artışıyla 5 kat arttığını belirlemiş̧lerdir. Ayrıca araştırmacılar uygulanan trifluralin dozunun artmasıyla birlikte buharlaşma miktarının da arttığını ve üst katmanlardaki buharlaşmanın toprağın alt katmanlarına oranla daha fazla olduğunu ve buharlaşmanın rutubet ile orantılı olduğunu tespit etmişlerdir. Farklı iklim koşullarında trifluralin buharlaşmasını inceleyen Grass ve ark. (1994) en yüksek buharlaşma oranının $20^{\circ} \mathrm{C}$ sıcaklıkta, $1,2 \mathrm{~m} / \mathrm{s}$ rüzgâr hızında ve \%78 nem şartlarında olduğunu tespit etmişlerdir. Savage ve Barrentie (1969)'e göre yüzeye daha yakın yapılan trifluralin uygulamalarında buharlaşma şeklindeki kayıplar fazladır ve trifluralinin toprakta parçalanmadan kalabilmesi doğrudan toprağa karıştırma derinliğine bağlıdır. Benzer bir çalışma yapan Menges ve Tamez (1974) trifluralinin derinlere uygulanmasının kalıcılı̆̆ını artırdığını tespit etmişlerdir. Trifluralinin alüviyal arazilerde yüzey akış ile kayıplarını inceleyen Southwick ve ark. (1997), drenaj sisteminin uygulanması ile yüzey akış ile gerçekleşen trifluralin kayıplarının \%90 oranında azaldığını belirtmişlerdir. Trifluralinin topraktan buharlaşma ile kayıplarının nedenlerinden bir diğerinin de toprak işleme olduğunu vurgulayan Berger ve ark. (1999), toprağın işlenmesi, trifluralinin buharlaşma yolu ile kayıplarını arttırmıştır. Trifluralin ana maddesinin yüksek oranda buharlaşması ve toprakta parçalanarak türevler oluşturmasının yanı sıra su ortamında Tissier ve ark. (2005) göre photolysis ve hidrolysis şeklinde de parçalanmaktadır.

\section{Sonuç}

Arazi çalışmasında, sulama suyu olarak kullanılan kuyu sularında trifluralin kalıntı miktarları, bu kuyuları çevreleyen arazilerden seçilen ve farklı katmanları incelenen topraklardaki trifluralin kalıntıları incelenmiş olup, ilkbaharda yapılan toprak örneklemelerinde trifluralin kalıntı miktarları sonbaharda yapılan toprak örneklemelerinde belirlenen kalıntı miktarlarına oranla daha yüksek olmuştur. Profilin farklı katmanlarında yapılan incelemelerde, toprağın ilk $30 \mathrm{~cm}$ 'lik kısmında kalıntı konsantrasyonları genellikle yüksek olurken, alt katlara inildikçe kalıntı oranlarında azalmalar gözlenmiştir. Çalışma alanında incelenen topraklarda trifluralin uygulaması yapılan alanlarda kalıntı konsantrasyonları yüksek iken, trifluralin uygulanmayan topraklarda kalıntı miktarları oldukça düşüktür.

\section{Kaynaklar}

Arias-Estevez M, Lopes-Periago E, Martines-Karballoe, Simal-Gandara J, Mejusto Jc, Garcia-Rio L, 2008. The mobility and degradation of pesticides in soils and the pollution of groundwater resources. Agriculture, Ecosystems \& Environment 123: 247-260.

Bedos C, Rousseau-Djabri Mf, Flura D, Masson S, Barriuso E, Cellier P, 2002. Rate of pesticide volatilization from soil: an experimental approach with a wind tunnel system applied to trifluralin. Atmospheric Environment 36(39): 5917-5925.

Bedos C, Rousseau-Djabri Mf, Gabrielle B, Flura D, Durand B, Barriuso E, Cellier P, 2006. Measurement of trifluralin volatilization in the field: relation to soil residue and effect of soil incorporation. Environmental Pollution 144(3): 958-966.

Bengtson RL, Southwick LM, Willis GH, Cater CE, 1990. The influence of subsurface drainage practice on herbicide losses. American Society of Agricultural Engineers 33: 415-419.

Berger Bm, Duehlmeier D, Siebert Cf, 1999. Tillage effects on persistence and istribution of trifluralin in soil. Journal of Environmental Quality 28 (4):1162-1167.

Boivin A, Cherrier R, Michel Schiavon M, 2005. A comparison of five pesticides adsorption and desorption processes in thirteen contrasting field soils. Chemosphere 61 (5): 668-676.

Dinç U, Şenol S, Kapur S, Atalay İ, Cangir C, 1995. Türkiye Toprakları. Ç.Ü Ziraat Fakültesi Genel Yayın No: 51 Ders Kitapları Yayın No:12 Adana.

Feagley SE, Kim JH, 1995. Adsorption and leaching of cis and tras-permethrin in the soil. Journal of Korean Environmental Science Society 4: 379-386.

Francioso O, Bak E, Rossi N, Sequi P, 1992. sorption of atrazine and trifluralin in relation to the physio-chemical characteristics of selected soils. The Science of The Total Environment 123-124: 503-512. 
Gardner Ds, Branham Be, 2001. Effect of turfgrass cover and irrigation on soil mobility and dissipation of mefenoxam and propiconazole. Journal of Environmental Quality 30: 1612-1618.

Grass B, Wenclawiak Bw, Rüdel H, 1994. influence of air velocity, air temperature, and air humidity on the volatilisation of trifluralin from soil. Chemosphere 28 (3): 491-499.

Harper LA, White AV, Bruce RR, Thomas AW, Leonard RA, 2000. Soil and microclimate effects on trifluralin volatilization. Soil Science 165 (9): 690-698.

Hollingsworth EB, 1980. Volatility of trifluralin from field soil. Weed Science 28(2): 224-228.

Johnstone Pk, Jolley Av, Code Gr, Moerkerk Mr, Corbett A, 1998. Degradation of trifluralin in three victorian soils-longterm field trials. Australian Journal of Experimental Agriculture 38(4): 363 - 374.

Kim JH, Feagley SE, 1998. Adsorption and leaching of trifluralin, metolachlor, and metribuzin in a commerce soil. Journal of Environmental Science and Health 33(5): 529-546.

Kim JH, Feagley SE, 2002. Leaching of trifluralin, metolachlor, and metribuzin in a clay loam soil of louisiana. Journal of Environmental Science and Health, Part B. 37(5): 393-403.

Kodesova R, Kocarek M, Kodes V, Drabek O, Kozak J, Hejtmankova K, 2011. Pesticide adsorption in relation to soil properties and soil type distribution in regional scale. Journal of Hazardous Materials 186: 540-550.

Menges RM, Tamez S, 1974. Movement and persistence of bensulide and trifluralin in irrigated soil. Weed Science 22(1): 67-71.

Moore MT, Lizotte RE, Knifht SS, Smith S, Copper CM, 2007. Assessment of pesticide contamination in three Mississippi Delta oxbow lakes using Hyalella azteca. Chemosphere 67(11):2184-2191.

Moyer JR, 1979. Soil organic matter, moisture, and temperature: effect on wild oats control with trifluralin. Canadian Journal of Plant Science 59(3): 763-768.

Müller K, Magesan GN, Bolan NS, 2007. A critical review of the influence of effluent irrigation on the fate of pesticides in soil. Agriculture, Ecosystems \& Environment 120: 93-116.

Nelson SD, Letey J, Farmer WJ, Williams CF, Ben-Hur M, 2000. Herbicide application method effects on napropamide complexation with dissolved organic matter. Journal of Environmental Quality 29: 987-994.

Nelson SD, Letey J, Farmer WJ, Williams CF, Ben-Hur M, 2000. Herbicide application method effects on napropamide complexation with dissolved organic matter. Journal of Environmental Quality 29: 987-994.

Pintar M, Pilk M, Lobnik F, Hudnik V, Zupan M, Carpi E, Evans SP, Trevisan M, 1996. Mobility, leaching and degradation of atrazine in columk and field experiments. Water Management Institute, Hajdrihova 28, 1000 Ljubljana, Slovenia.

Querejeta GA, Ramos LM, Hughes EA, Vullo D, Zalts A, Montserrat JM, 2014. Environmental fate of trifluralin, procymidone and chlorpyrifos in small horticultural production units in Argentina. Water, Air, \& Soil Pollution 225:1952.

Sağlam MT, 1994. Toprak ve Suyun Kimyasal Analiz Yöntemleri. T.Ü. Tekirdağ Ziraat Fakültesi yayınları, Tekirdağ.

Savage KE, Barrentine WL, 1969. Trifluralin persistence as affected by depth of soil incorporation. Weed Science 17 (3): 349-352.

Southwick LM, Willis GH, Mercado OA, Bengtson RL, 1997. Effect of subsurface drains on runoff losses of metolachlor and trifluralin from mississippi river alluvial soil. Archives of Environmental Contamination and Toxicology 32(1):106-9.

Spencer WF, Cliath MM, 1974. Factors affecting vapor loss of trifluralin from soil. Journal of Agricultural and Food Chemistry 22(6): 987-991.

Tavares M, Rezende M, 1998. Effect of humic acid on the sorption of trifluralin by soils. Journal of Environmental Science and Health, Part B. 33 (6): 749-767.

Tissier C, Morvan C, Bocquené G, Grossel H, James A, Marchand M, 2005. Les bstances prioritaires de la Directive cadre sur l'eau (DCE). Fiches de synthèse Rapportlfremer. Erişim Adresi: www.ifremer.fr/delpc/pdf/RAPPORT_FICHES33_SUBSTANCES.pdf

Tok HH, 1996. Trakya Bölgesinde Pestisit Kullanımı ve Pestisitlerin Çevre Üzerindeki Olumsuz Etkileri. Trakya Tarım ve Çevre Sempozyumu, Çorlu.

Tok HH, 1997. Çevre Kirliliği. T.Ü. Tekirdağ Ziraat Fakültesi, Ders Kitabı, Tekirdağ. 